\title{
Inducibility of ventricular arrhythmias in Chronic Chagas disease predicted by clinical scores.
}

\author{
Bruno Valdigem ${ }^{1}$, rogerio andalaft ${ }^{1}$, Dalmo Moreira $^{2}$, Luciana Armaganijan ${ }^{2}$, felipe \\ oliveira $^{1}$, Leandro Faria ${ }^{1}$, ricardo habib ${ }^{1}$, eduardo barbaroto $^{1}$, izaias Sa junior ${ }^{1}$, and \\ DIEGO PIMENTA ${ }^{3}$
}

\author{
${ }^{1}$ Dante Pazzanese Cardiological Institute \\ ${ }^{2}$ Dante Pazzanese Institute of Cardiology \\ ${ }^{3}$ Instituto Dante Pazzanese de Cardiologia
}

April 12, 2021

\begin{abstract}
BACKGROUND Electrophysiologic Study (EPS) is a diagnostic tool that can further evaluate patients prone to arrhythmic death.OBJECTIVE To shed light on the causes of death in Chagas disease, specially on regards of importance of the VT induction and chances of death, as evaluated by Rassi clinical score. METHODS We evaluated data from 153 patients with Chagas disease from the electrophysiology laboratory from a tertiary center between January of 2011 and January 2013 . All patients were evaluated with 1, 2, 3 or 4 ventricular extra-stimuli followed by runs of 10 beats fast ventricular stimulation. If VT or VF is inducible the patients are referred to ICD implant or VT ablation. RESULTS Of a total of 153 patients, $48 \%$ were male, mean age $58 \pm 12$ years (24 - 84 years). As for risk of death according to the clinical score, $32 \%$ were evaluated as low risk, 35,4\% intermediate, 32,6\% high risk. NSVT on 24 hour Holter ( $\mathrm{p}=0,009)$, stimulation on EPS ( $<<0,001)$, lower VEFE $(\mathrm{p}<0,01)$, cardiomegaly $(\mathrm{p}<0,001)$ and high risk on Rassi score $(\mathrm{p}<0,001)$ where the more associated variables to ventricular tachyarrithmias. CONCLUSIONS Clinical score is an interesting tool to further stratify patients in higher risk for VT induction during EPS, which is also a marker of higher risk of sudden cardiac death. Some characteristics as Non sustained VT, Pulmonary congestion, cardiomegaly and low voltage QRS were the most relevant determinants for inducible VT on EPS. The duration of NSVT is also important for VT induction in EPS.
\end{abstract}

\section{Hosted file}

chagas.pdf available at https://authorea.com/users/407303/articles/517639-inducibility-ofventricular-arrhythmias-in-chronic-chagas-disease-predicted-by-clinical-scores 